\title{
Immobilization of Horseradish Peroxidase to Electrochemically Deposited Gold-Nanoparticles on Glassy Carbon Electrode for Determination of $\mathrm{H}_{2} \mathrm{O}_{2}$
}

\author{
Hyunwoo Ryoo, Yousung Kim, ${ }^{\dagger}$ Junghyun Lee, ${ }^{\dagger}$ Woonsup Shin, ${ }^{\dagger}$ Noseung Myung, ${ }^{\ddagger}$ and Hun-Gi Hong ${ }^{*}$ \\ Department of Chemistry Education, Seoul National University, Seoul 151-742, Korea. *E-mail: hghong@snu.ac.kr \\ ${ }^{\dagger}$ Department of Chemistry and Interdisciplinary Program of Integrated Biotechnology, Sogang University, Seoul 121-742, Korea \\ ¿Department of Applied Chemistry, Konkuk University, Chungju Campus, Chungju, Chungbuk 380-701, Korea \\ Received February 8, 2006
}

\begin{abstract}
A new approach to fabricate an enzyme electrode was described based on the immobilization of horseradish peroxidase (HRP) on dithiobis- $N$-succinimidyl propionate (DTSP) self-assembled monolayer (SAM) formed on gold-nanoparticles (Au-NPs) which were electrochemically deposited onto glassy carbon electrode (GCE) surface. The overall surface area and average size of Au-NPs could be controlled by varying deposition time and were examined by Field Emission-Scanning Electron Microscope (FE-SEM). The $\mathrm{O}_{2}$ reduction capability of the surface demonstrated that Au-NPs were thermodynamically stable enough to stay on GCE surface. The immobilized HRP electrode based on Au-NPs/GCE presented faster, more stable and sensitive amperometric response in the reduction of hydrogen peroxide than a HRP immobilized on DTSP/gold plate electrode not containing Au-NPs. The effects of operating potential, mediator concentration, and $\mathrm{pH}$ of buffer electrolyte solution on the performance of the HRP biosensor were investigated. In the optimized experimental conditions, the HRP immobilized GCE incorporating smaller-sized Au-NPs showed higher electrocatalytic activity due to the high surface area to volume ratio of Au-NPs in the biosensor. The HRP electrode showed a linear response to $\mathrm{H}_{2} \mathrm{O}_{2}$ in the concentration range of $1.4 \mu \mathrm{M}-3.1 \mathrm{mM}$. The apparent Michaelis-Menten constant $\left(\mathrm{K}_{\mathrm{M}}{ }^{\text {app }}\right)$ determined for the immobilized HRP electrodes showed a trend to be decreased by decreasing size of Au-NPs electrodeposited onto GCE.
\end{abstract}

Key Words : Gold-nanoparticles, Glassy carbon electrode, Horseradish peroxidase, Hydrogen peroxide

\section{Introduction}

There has been considerable attention in the immobilization of redox enzymes on electrode surfaces for fabrication of bioelectronic devices and electrochemical biosensors. ${ }^{1}$ These enzyme-based amperometric biosystems usually show high specificity and sensitivity in analysis of biologically important substances because they employ enzyme as a bioelectrocatalyst. Among these analytes, hydrogen peroxide has been detected to characterize performance of many electrochemical biosensors because it is not only an important by-product formed from a lot of peroxidase-catalyzed reactions but also a signal transducer molecule in food, clinical, pharmaceutical, industrial, and environmental assays. ${ }^{2-4}$ Recently, the conjugation of nanoparticles with biomaterials has been intensively studied because it provides electronic or optical transduction of a variety of biological phenomena. For example, Crumbliss and co-workers ${ }^{5,6}$ have shown that the activity of enzymes adsorbed on colloidal Au sols, a kind of biomoleculenanoparticle conjugate, is well retained when deposited onto conducting matrixes. After their findings, gold-nanoparticle (Au-NP) has been extensively used in the fabrication of HRP biosensors to detect hydrogen peroxide. Chen et al. ${ }^{7}$ investigated $\mathrm{H}_{2} \mathrm{O}_{2}$ reduction in the presence of catechol as a mediator using HRP-labeled Au colloid attached to SAM on gold. However, Dong et al. ${ }^{8}$ reported a novel method constructing a mediatorless third-generation HRP biosensor, which is developed by self-assembling gold-nanoparticles to a thiol-containing sol-gel network. Yu and co-workers studied the immobilized HRP on the nano-Au monolayer modified chitosan-entrapped carbon paste electrode ${ }^{9}$ and $\mathrm{GCE}^{10}$ and reported the detection limit of $c a$. $6.3 \mu \mathrm{M}$ in determination of hydrogen peroxide. All these reports utilize the direct adsorption of HRP on gold-nanocolloidal particle which is chemisorbed on SAM or incorporated in polymer matrix.

In this paper, we describe a new approach to immobilize HRP enzyme on GCE using molecular self-assembly ${ }^{11}$ and electrochemical deposition of gold nanocrystallites. ${ }^{12,13}$ The self-assembled monolayer of alkanethiolate on gold has been used as a powerful procedure for construction of welldefined chemical interface due to its simplicity, versatility, and convenience. In recent years, McDermott and Finot ${ }^{12}$ reported that the size and spatial density of electrochemically deposited gold nanocrystal can be controlled by deposition condition. The combination of these methods is our platform to build a novel HRP-based amperometric sensor. First of all, well-dispersed gold nanocrystals are used as a support for formation of monolayer by the chemisorption of dithiobis- $N$-succinimidyl propionate (DTSP) as an enzyme cross-linking reagent for HRP immobilization. In addition, the gold-nanoparticles (Au-NPs) deposited onto GCE provide higher electrocatalytic activity than that of a planar gold electrode. With combining these advantages of self-assembly, nanoparticle, and bioenzyme, a novel HRP 
immobilized biosensor has been developed and its amperometric response and factors influencing the performance of the biosensor have been studied in this work. Especially, this electrochemical enzyme biosensor shows the size-dependent electrocatalytic activity of Au-NPs electrodeposited onto GCE surface toward the reduction of $\mathrm{H}_{2} \mathrm{O}_{2}$ in the presence of hydroquinone as a mediator.

\section{Experimental Section}

Materials and Reagents. Glassy carbon (GC) plate (10 $\mathrm{cm} \times 10 \mathrm{~cm} \times 3 \mathrm{~mm}$ in dimension) was obtained from Tokai Carbon Co. for SEM sample preparation. Horseradish peroxidase (EC 1.11.1.7, 120 unit/mg solid, m.w. 44 kDa) and dithiobis-N-succinimidyl propionate (DTSP) were purchased from Sigma and stored as received at $-20{ }^{\circ} \mathrm{C}$. Sodium tetrachroloaurate(III) and dimethyl sulfoxide anhydrate (DMSO) were obtained from Sigma. Disodium hydrogen phosphate and potassium dihydrogen phosphate (Junsei) were used in the preparation of a buffer solution. Hydrogen peroxide, hydroquinone, and sulfuric acid were of analytical grade and purchased from Junsei Chemical. Hydrogen peroxide stock solution was prepared by diluting a $30 \%$ solution. The accurate concentration of $\mathrm{H}_{2} \mathrm{O}_{2}$ solution was determined with the absorbance measurement at $240 \mathrm{~nm}$ using extinction coefficient of $39.4 \mathrm{mM}^{-1} \mathrm{~cm}^{-1}$. ${ }^{14}$ Milli-Q water (Millipore, Japan) was used to prepare all aqueous solutions.

Electrochemical Measurements. Electrochemical measurements were carried out in a single compartment cell with a platinum wire counter electrode, an $\mathrm{Ag} / \mathrm{AgCl} / \mathrm{KCl}$ (sat'd) electrode as a reference electrode, and HRP immobilized GC (3 $\mathrm{mm}$ in diameter) working electrode. Voltammetric experiments were performed using a computer-controlled $\mathrm{CHI}$ 760B electrochemical analyzer ( $\mathrm{CH}$ Instrument $\mathrm{Co}$.) and carried out at room temperature. Cyclic voltammetry experiments were done in quiescent solution. Amperometric measurements of HRP enzyme-modified electrode were performed in a stirred solution after a steady-state background current had been obtained prior to addition of $\mathrm{H}_{2} \mathrm{O}_{2}$ standard solution into the buffer solution. In order to obtain a steady-state current-time curve, aliquots of $\mathrm{H}_{2} \mathrm{O}_{2}$ standard solution was successively added to the buffer solution with microsyringe. Phosphate buffer solution (PBS) (0.1M, pH 7.0) prepared with $\mathrm{KH}_{2} \mathrm{PO}_{4}$ and $\mathrm{Na}_{2} \mathrm{HPO}_{4}$ was used in the amperometric measurements. All experimental solutions were purged with $\mathrm{N}_{2}$ at least 15 min before use, and were kept with $\mathrm{N}_{2}$ blanket during measurements.

Electrochemical Deposition of Au-NPs on GCE. In order to obtain FE-SEM image of electrochemically deposited Au-NPs, a large GC plate was cut into small pieces of 1.5 $\mathrm{cm} \times 1.5 \mathrm{~cm} \times 3 \mathrm{~mm}$ in dimension. Before electrodeposition, the small GC plate electrode was polished with 1.0-, 0.3-, and $0.05-\mu \mathrm{m}$ alumina slurry on a polishing microcloth, and sonicated in Mill-Q water for $10 \mathrm{~min}$. A home-made electrochemical cell, similar to reported in the literature, ${ }^{15}$ is mounted on the polished GC plate electrode with a Vitron Oring between them. The electrode surface area confined by the O-ring is $c a .0 .38 \mathrm{~cm}^{2}$. Au-nanoparticles from $0.5 \mathrm{M}$ $\mathrm{H}_{2} \mathrm{SO}_{4}$ solution containing $1.0 \mathrm{mM} \mathrm{NaAuCl} \mathrm{m}_{4}$ were electrodeposited on the GC plate electrode by applying a potential step from 1.1 to $0.0 \mathrm{~V}$ vs. $\mathrm{Ag} / \mathrm{AgCl} / \mathrm{KCl}$ (sat'd). The deposition time was varied from 3 to $600 \mathrm{~s}$ to obtain Au-NPs with different characteristics in size and surface density. Oxygen reduction was performed at both a bare GCE and an Au-NP deposited GCE in an $\mathrm{O}_{2}$-saturted 0.1 M PBS of $\mathrm{pH} 7.0$ to ascertain the electrocatalytic activity of Au-NPs deposited onto GCE.

SEM Imaging. FE-SEM image of Au-NPs deposited onto GC plate under different deposition condition was characterized using scanning electron microscope (JEOL JSM-6700F) at the acceleration voltage of $5-30 \mathrm{kV}$ and a working distance of 6-19 mm.

HRP Enzyme Immobilization on Au-NP Deposited onto GC Disk Electrode. Scheme 1. shows the fabrication procedure to prepare a HRP enzyme-immobilized amperometric biosensor based on Au-NPs electrodeposited onto GCE. First, GC disk electrode (6 $\mathrm{mm}$ in diameter) was polished, pre-cleaned, and finally electrochemically deposited with Au-NP on its surface in the same manners as described in the previous section. The resulting Au-NPs/ GCE was thoroughly rinsed with deionized water and DMSO. This electrode was immersed in DMSO solution containing $4 \mathrm{mM}$ DTSP for $1 \mathrm{~h}$ at room temperature. The Au-NPs/GCE modified with DTSP SAM was thoroughly rinsed with DMSO, acetone, and was conditioned in $0.1 \mathrm{M}$ PBS ( $\mathrm{pH} 7.0$ ) for $1 \mathrm{~h}$. According to the report by Abruna et al., ${ }^{16}$ the resulting DTSP/Au-NPs/GCE electrode was immersed in a $0.1 \mathrm{M}$ PBS ( $\mathrm{pH}$ 7.0) containing HRP enzyme at a concentration of $1.0 \mathrm{mg} / \mathrm{mL}$ and kept for $24 \mathrm{~h}$ at $4{ }^{\circ} \mathrm{C}$. After copious rinsing the enzyme modified electrode with phosphate buffer, it was stored in $0.1 \mathrm{M}$ PBS at $4{ }^{\circ} \mathrm{C}$ when not used.

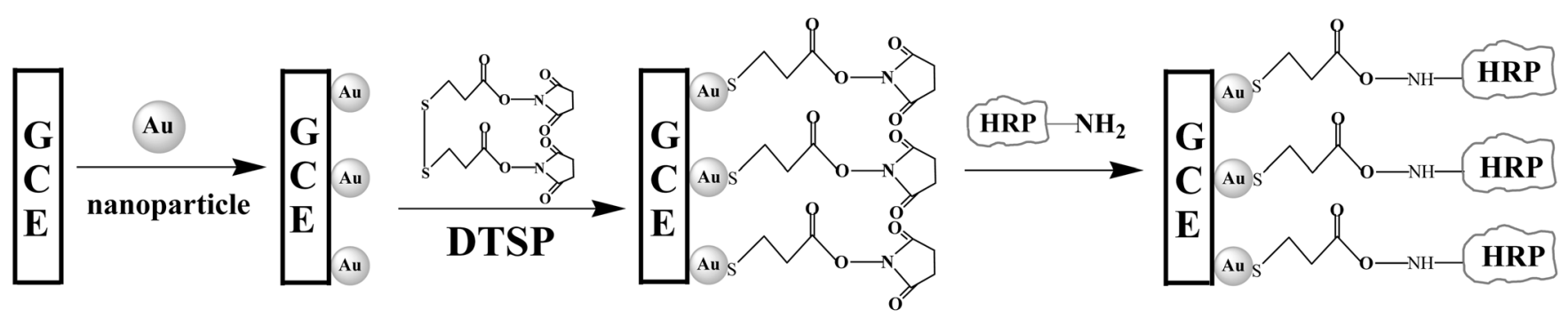

Scheme 1. Stepwise fabrication procedure of a HRP/DTSP/Au-NPs/GCE. 


\section{Results and Discussion}

Characterization of Au-NPs on GCE. The Au-NPs electrodeposited onto GCE under different deposition conditions were studied with scanning electron microscopy. And the typical FE-SEM images of the Au-NPs on GCE are shown in Figure 1. These micrographs indicate that the size and surface density of Au-NP can be controlled by applying a different electrochemical deposition time. Recently, McDermott and Finot ${ }^{12}$ reported the effects of concentration of tetrachloroaurate(III) ion and deposition potential on the size of Au-nanocrystals, which were electrochemically deposited onto GCE. In reality, Au-NP at first grows slowly on glassy carbon surface during the reduction process of $\mathrm{AuCl}_{4}{ }^{-}$ions in acidic solution. However, its average size and surface density increase as the electrodeposition time becomes longer. The similar trend of Au-nanoparticle growth observed in our work has been also reported by Ohsaka et al. ${ }^{17}$ In order to estimate total surface area of Au-NPs deposited onto GCE, cyclic voltammogram (CV) of each $\mathrm{Au}-\mathrm{NPs} / \mathrm{GCE}$ was measured in $0.05 \mathrm{M} \mathrm{H}_{2} \mathrm{SO}_{4}$ solution (Figure 2). These background CVs show that the electrochemically deposited Au-NPs behave like pure polycrystalline gold electrodes in the anodic potential range. The gold surface oxide reduction peak current at $c a .0 .86 \mathrm{~V}$ increases with increase in the deposition time. The real surface area of $\mathrm{Au}-\mathrm{NPs}$ was estimated from the area under the gold oxide reduction peak using the reported value of $400 \mu \mathrm{C} / \mathrm{cm}^{2}{ }^{18}$ The average Au-nanoparticle size and the gold surface area values of Au-NPs formed under different deposition condition were estimated from the SEM micrographs and summarized in Table 1.

Before the immobilization of HRP enzyme on Au-NPs/ GCE, we examined the electrocatalytic activity of the Au$\mathrm{NP}$ in reduction of $\mathrm{O}_{2}$ because the electrochemical durability
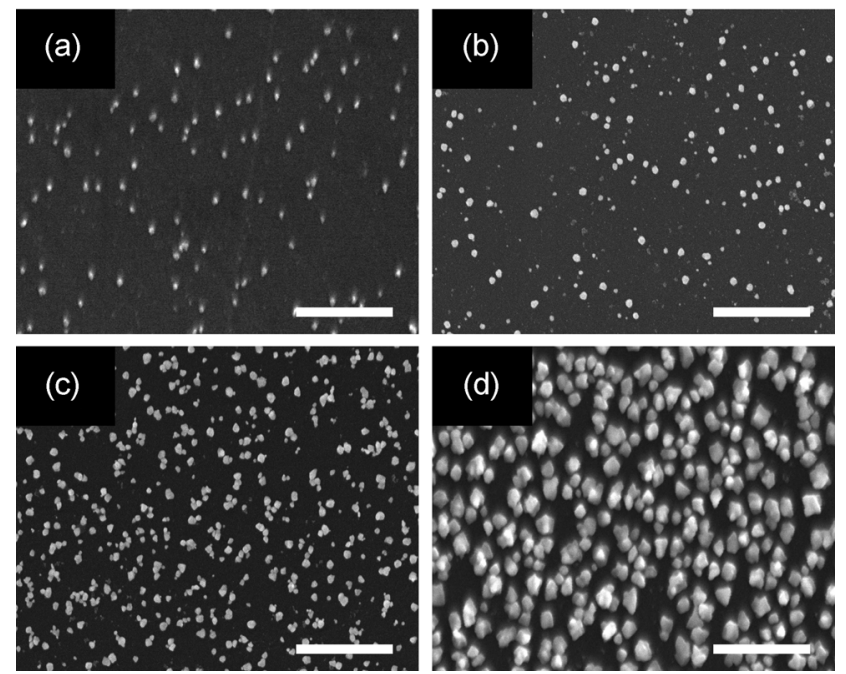

Figure 1. FE-SEM micrographs of the electrochemically deposited gold-nanoparticles on GCE from $1 \mathrm{mM} \mathrm{NaAuCl} / 4 / 0.5 \mathrm{M} \mathrm{H}_{2} \mathrm{SO}_{4}$ solution. Electrodeposition time: (a) 3, (b) 5, (c) 120, and (d) $600 \mathrm{~s}$. Potential step from 1.1 to $0.0 \mathrm{~V} v s$. $\mathrm{Ag} / \mathrm{AgCl} / \mathrm{KCl}$ (sat'd) was used. Length of white bar in micrographs $=1.0 \mu \mathrm{m}$.

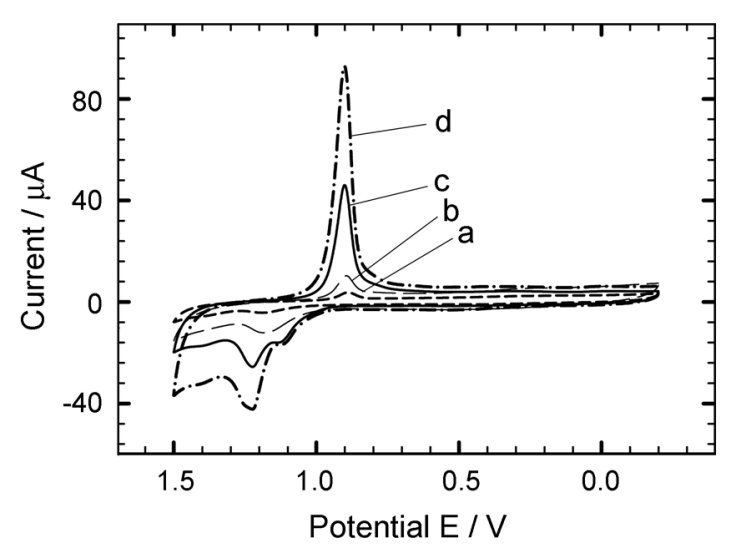

Figure 2. Typical cyclic voltammograms obtained in $\mathrm{N}_{2}$-saturated $0.05 \mathrm{M} \mathrm{H}_{2} \mathrm{SO}_{4}$ for Au-NPs/GCEs formed under the different electrodeposition time: (a) 3, (b) 5, (c) 120, and (d) $600 \mathrm{~s}$ with a same potential step from 1.1 to $0.0 \mathrm{~V} v s$. $\mathrm{Ag} / \mathrm{AgCl} / \mathrm{KCl}$ (sat'd) was used. All scan rates were $100 \mathrm{mV} \mathrm{s}^{-1}$.

Table 1. The average size and total surface area of electrochemically deposited Au-nanoparticles on GCE

\begin{tabular}{cccc}
\hline $\begin{array}{c}\text { Electrode } \\
\text { no. }\end{array}$ & $\begin{array}{c}\text { Deposition time } \\
(\mathrm{sec})\end{array}$ & $\begin{array}{c}\text { Average size } \\
(\mathrm{nm})\end{array}$ & $\begin{array}{c}\text { Average surface area } \\
\text { of Au loading }\left(\mathrm{cm}^{2}\right)\end{array}$ \\
\hline 1 & 3 & $31 \pm 8$ & $5.4 \pm 10^{-3}$ \\
2 & 5 & $40 \pm 15$ & $2.1 \pm 10^{-2}$ \\
3 & 120 & $59 \pm 25$ & $8.9 \pm 10^{-2}$ \\
4 & 600 & $138 \pm 54$ & $1.9 \pm 10^{-1}$ \\
\hline
\end{tabular}

and stability of Au-NPs electrodeposited onto GCE is of importance for further modification. Figure 3 shows typical $\mathrm{CVs}$ for $\mathrm{O}_{2}$ reduction at a bare GCE and an Au-NPs/GCE in $\mathrm{O}_{2}$-saturated phosphate buffer solution of $\mathrm{pH}=7.0$. In Figure $3 \mathrm{a}$, the first reduction peak at $c a .-828 \mathrm{mV}$ is due to the $\mathrm{O}_{2}$ reduction to $\mathrm{H}_{2} \mathrm{O}_{2}$, and the second peak at $c a$. -1380 $\mathrm{mV}$ is due to the $\mathrm{H}_{2} \mathrm{O}_{2}$ reduction to $\mathrm{H}_{2} \mathrm{O}$. However, the two reduction peaks largely shift in the positive direction to $c a$. -220 and $-633 \mathrm{mV}$ as shown in Figure 3b, respectively. The positive potential shifts indicate that Au-NPs catalyze two successive 2e- reduction processes of $\mathrm{O}_{2}$. A similar result has been reported for Au-NPs deposited onto GCE in reduction of $\mathrm{O}_{2} \cdot{ }^{17}$ In order to check the electrochemical stability of Au-NPs deposited onto GCE, continuous potential cycling was conducted in the $\mathrm{O}_{2}$ reduction potential range from 0.0 to $-1.0 \mathrm{~V} \mathrm{vs.} \mathrm{Ag} / \mathrm{AgCl} / \mathrm{KCl}$ (sat'd) for $40 \mathrm{~min}$ in $0.1 \mathrm{M}$ PBS ( $\mathrm{pH}=7.0$ ). However, we could not observe any change in the cyclic voltammogram $b$ in Figure 3. This fact demonstrates that Au-NPs were strongly adhered to a glassy carbon electrode surface.

Electrochemical Characterization of a HRP/DTSP/ Au-NPs/GCE. Figure 4 shows the CVs obtained for both a DTSP/Au-NPs/GCE and a HRP enzyme-immobilized DTSP/ $\mathrm{Au}-\mathrm{NPs} / \mathrm{GCE}$ in a $\mathrm{N}_{2}$-saturated 0.1 M PBS ( $\left.\mathrm{pH}=7.0\right)$. First of all, the Figure 4a indicates that the HRP/DTSP/Au-NPs/ GCE does not show the direct electron transfer between a heme group of HRP and a GC electrode, resulting in no voltammetric wave. When hydroquinone (HQ) as a diffu- 


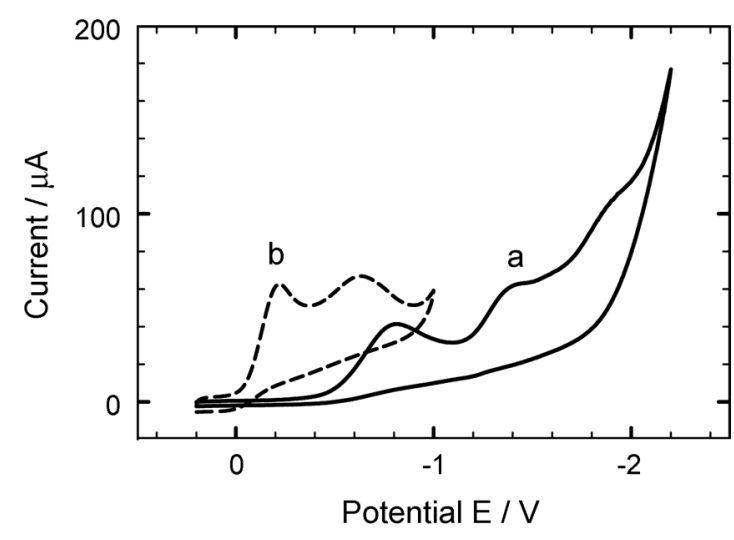

Figure 3. Cyclic voltammograms in $\mathrm{O}_{2}$-saturated 0.1 M PBS (pH $=7.0$ ) at a bare GCE(a) and an Au-NPs/GCE formed with electrodeposition time (600 s) (b). Potential scan rate: $100 \mathrm{mV} \mathrm{s}^{-1}$.

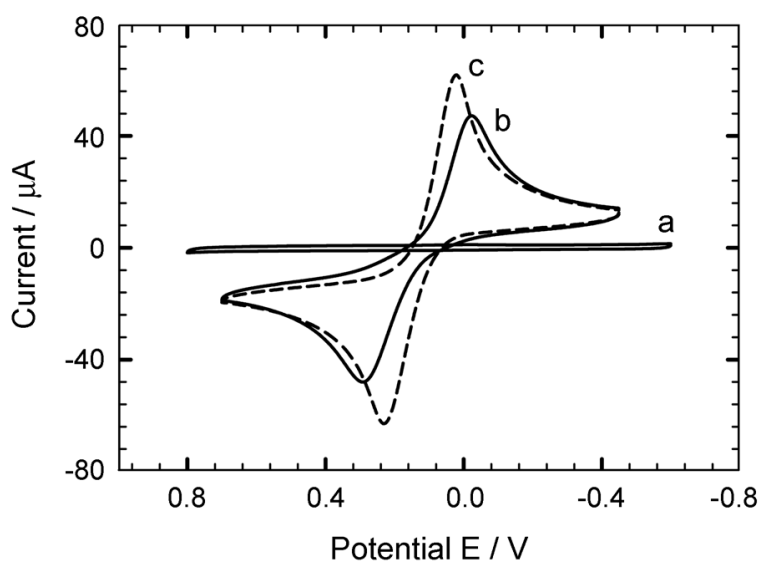

Figure 4. Cyclic voltammograms in $\mathrm{N}_{2}$-saturated $0.1 \mathrm{MPBS}(\mathrm{pH}=$ 7.0) at a HRP/DTSP/Au-NPs/GCE (a, b) and a DTSP/Au-NPs/ GCE(c). Scan rate : $100 \mathrm{mV} \mathrm{s}^{-1}$. CVs were observed in the buffer solution without hydroquinone (a) and with $2.0 \mathrm{mM}$ hydroquinone $(b, c)$.

sional mediator was added, the enzyme-modified electrode shows the Figure $4 \mathrm{~b}$ in which a pair of redox peaks is observed due to $2 \mathrm{e}^{-}, 2 \mathrm{H}^{+}$coupled redox reaction of $\mathrm{HQ}$ molecule. However, the peak separation of $c a .314 \mathrm{mV}$ in the Figure $4 \mathrm{~b}$ decreases down to that of $c a .209 \mathrm{mV}$ in the Figure $4 \mathrm{c}$, which is observed at the DTSP/Au-NPs/GCE in the presence of HQ. The decrease in the peak-to peak separation clearly indicates the faster heterogeneous electron transfer of HQ at DTSP/Au-NPs/GCE than at HRP/DTSP/ $\mathrm{Au}-\mathrm{NPs} / \mathrm{GCE}$. This phenomenon is due to the easier accessibility of the diffusional mediator to an electrode surface in the absence of an immobilized HRP. Figure 5 shows cyclic voltammetric responses for the HRP modified electrode in the presence of HQ. When $\mathrm{H}_{2} \mathrm{O}_{2}$ was absent, only $\mathrm{HQ}$ in solution gives its diffusional redox wave. However, in addition of $0.5 \mathrm{mM}$ hydrogen peroxide to $0.1 \mathrm{M}$ PBS ( $\mathrm{pH}=7.0$ ), the reduction peak current remarkably increases and the oxidation current consequently decreases. This electrocatalytic behavior presents that $\mathrm{HQ}$ has a capability of mediating electron transfer from the GC electrode to the redox center

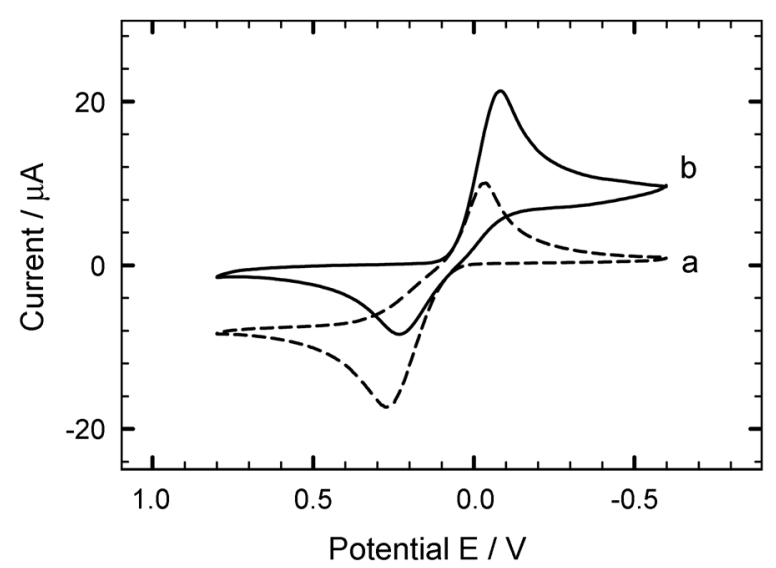

Figure 5. Cyclic voltammograms of a HRP/DTSP/Au-NPs/GCE in $0.1 \mathrm{M}$ PBS $(\mathrm{pH}=7.0)$ containing $2.0 \mathrm{mM}$ hydroquinone in the absence (a) and presence (b) of $0.5 \mathrm{mM} \mathrm{H}_{2} \mathrm{O}_{2}$. Scan rate: $10 \mathrm{mV} \mathrm{s}^{-1}$.

of HRP immobilized to DTSP/Au-NPs/GCE even at the redox potential of HQ. The similar results have been reported with HRP immobilized on nano-gold colloide film on cysteamine monolayer ${ }^{7}$ and chitosan film. ${ }^{9,10}$ Scheme 2 shows the electron relay mechanism for hydrogen peroxide reduction via HRP enzyme immobilized.

Optimization of Experimental Conditions. We studied the effect of experimental conditions on the amperometric sensitivity of the HRP modified electrode for the reduction of hydrogen peroxide. The experimental variables such as the applied potential, the concentration of mediator, and the $\mathrm{pH}$ of buffer solution can affect the performance of an enzyme-modified electrode. The amperometric response for hydrogen peroxide reduction was checked to find an appropriate applied potential by changing a potential from 50 to $-200 \mathrm{mV}$. The current response was well-stabilized with the lowest background current at $-50 \mathrm{mV}$ in $0.1 \mathrm{M}$ PBS. Since the sensitivity of the HRP modified electrode substantially decreased at potential lower than $-50 \mathrm{mV} v$. $\mathrm{Ag} / \mathrm{AgCl} / \mathrm{KCl}$ (sat'd), $-50 \mathrm{mV}$ was chosen for the amperometric measurements. Figure 6 shows the amperometric response due to concentration change of hydroquinone as a mediator for heterogeneous electron transfer of the immobilized HRP enzyme. The current response increased as increasing the mediator concentration and showed maximum at $2 \mathrm{mM}$, and decreased as increasing the concentration at

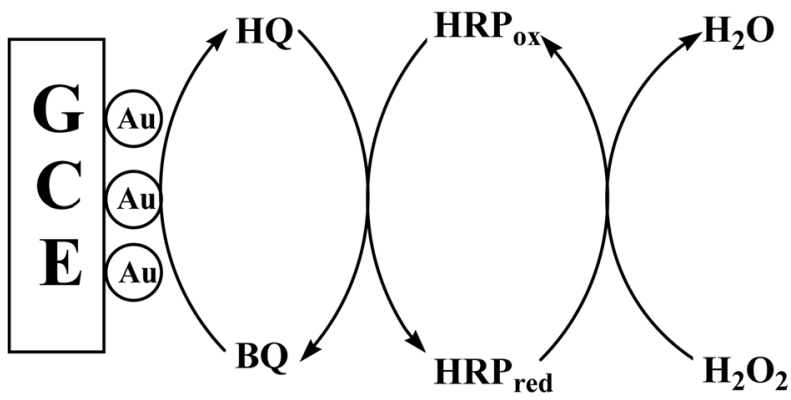

Scheme 2. Electron relay for electrochemical reduction of hydrogen peroxide on HRP/DTSP/Au-NPs/GCE. 


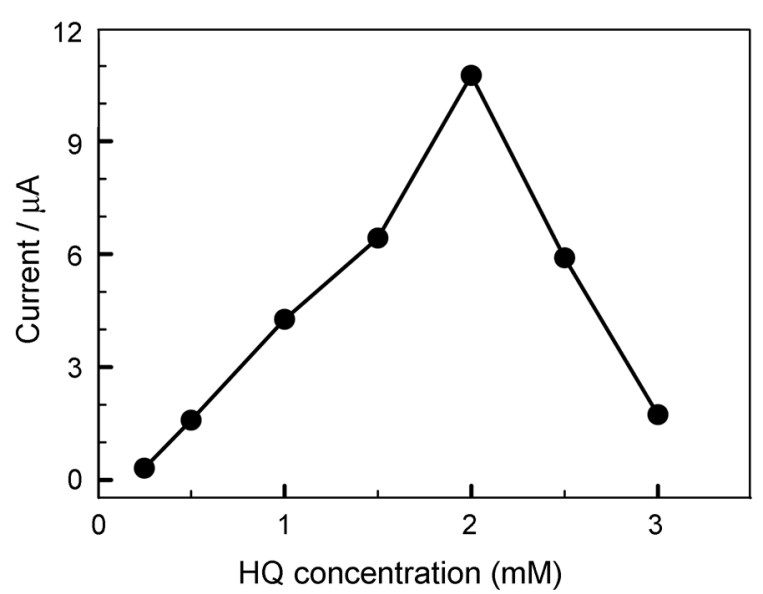

Figure 6. Plot of amperometric response of the HRP/DTSP/Au$\mathrm{NPs} / \mathrm{GCE}$ versus concentration of hydroquinone in $0.1 \mathrm{M} \mathrm{PBS}(\mathrm{pH}$ 7.0) containing $0.584 \mathrm{mM} \mathrm{H}_{2} \mathrm{O}_{2}$ at the applied pontential of -50 $\mathrm{mV}$.

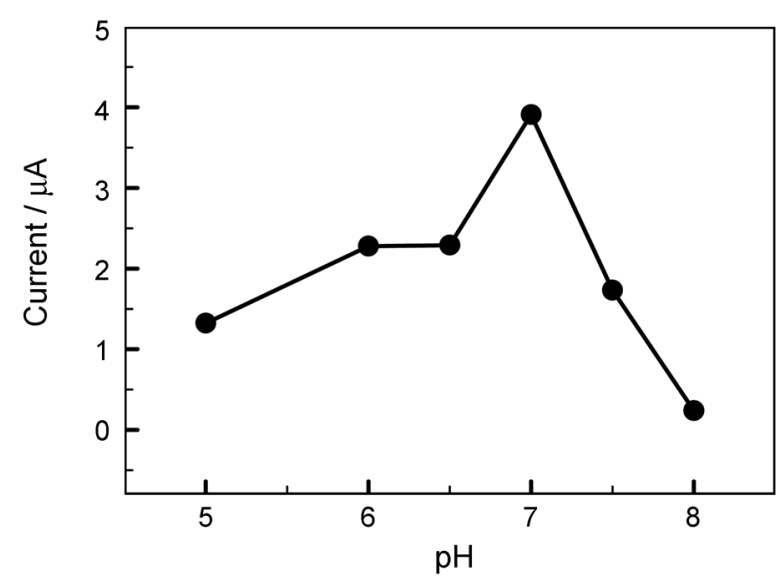

Figure 7. Plot of $\mathrm{pH}$ effect on the amperometric response of the HRP/DTSP/Au-NPs/GCE in phosphate buffer solution containing $0.264 \mathrm{mM} \mathrm{H}_{2} \mathrm{O}_{2}$ and $2.0 \mathrm{mM}$ hydroquinone. The applied potential was $-50 \mathrm{mV} v s$. $\mathrm{Ag} / \mathrm{AgCl} / \mathrm{KCl}$ (sat'd) electrode.

higher concentration than $2 \mathrm{mM}$. This result is slightly different from those previously reported ${ }^{9} 19$ in which the current response was leveled off afterward at a certain concentration (usually 1-2 mM of mediator) when hydroquinone concentration increased. This phenomenon might be due to not only the high background current incurred when the hydroquinone concentration is higher at the operation potential of $-50 \mathrm{mV}$ but also the limit by the enzyme-substrate kinetics. ${ }^{9}$ Figure 7 presents $\mathrm{pH}$ dependence of the current response of the HRP modified electrode in $0.1 \mathrm{M}$ PBS containing $2 \mathrm{mM}$ hydroquinone and 0.264 $\mathrm{mM}$ hydrogen peroxide. The maximum current response was observed at $\mathrm{pH} 7.0$ as expected, which is quite close to optimum $\mathrm{pH}$ reported for soluble plant peroxidases. ${ }^{20} \mathrm{We}$ used these optimum condition of $\mathrm{pH} 7.0$ and mediator concentration $(2 \mathrm{mM})$ for the remainder experiments.

Amperometric Characteristics of the HRP/DTSP/ Au-NPs/GCE. In order to characterize the electrocatalytic

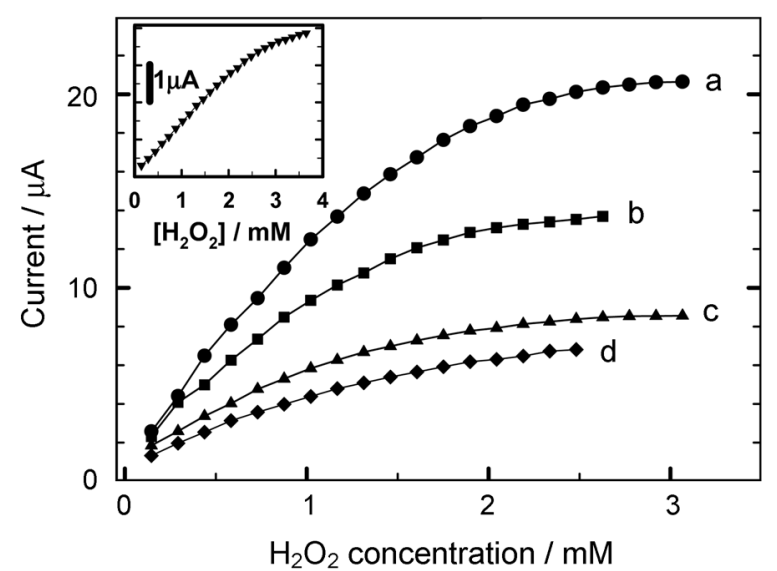

Figure 8. Typical calibration curve of HRP/DTSP/Au-NPs/GCEs prepared under different electrodeposition time of Au-NP: (a) 600s; (b) $120 \mathrm{~s}$; (c) $5 \mathrm{~s}$; (d) $3 \mathrm{~s}$. The curve in the inset was measured at HRP/DTSP/gold plate electrode under the same condition. Aliquot of $20 \mu \mathrm{L}$ of $36.5 \mathrm{mM} \mathrm{H}_{2} \mathrm{O}_{2}$ was successively added into $0.1 \mathrm{M}$ PBS $(\mathrm{pH}=7.0)$ containing $2.0 \mathrm{mM}$ hydroquinone at the applied potential of $-50 \mathrm{mV} v$ s. $\mathrm{Ag} / \mathrm{AgCl} / \mathrm{KCl}$ (sat'd).

response of the HRP modified electrode under the optimized experimental conditions, steady state chronoamperometric curve was measured at the applied voltage of $-50 \mathrm{mV}$ in a stirred PBS ( $\mathrm{pH} 7.0$ ) containing $2.0 \mathrm{mM}$ hydroquinone. Figure 8 shows typical steady state current calibration curves of HRP biosensors prepared on GCE and gold plate electrode for successive addition of $20 \mu \mathrm{L}$ of $36.5 \mathrm{mM}$ hydrogen peroxide in PBS. Au-nanoparticles were electrochemically deposited on GCE under different deposition time with the same potential step from 1.1 to $0.0 \mathrm{~V} v s$. $\mathrm{Ag} / \mathrm{AgCl} / \mathrm{KCl}$ (sat'd). The curve a, b, c, and d in Figure 8 were observed at HRP/DTSP/Au-NPs/GCEs in which the deposition time was $600,120,5$, and 3 s respectively. However, the curve in the inset was obtained at HRP/DTSP/gold plate electrode without deposition of Au-nanoparticle. The HRP modified on $\mathrm{Au}-\mathrm{NP} / \mathrm{GCE}$ shows faster and more sensitive current response to the addition of hydrogen peroxide when compared with the enzyme electrode not containing gold nanoparticle. This contrast indicates that Au-nanoparticle plays a role not only as a site for the spontaneous adsorption of DTSP monolayer but also as a catalytic center, the nature of nanosized metallic crystal on electrode surface. Figure 9 shows the linear calibration curve of a HRP/DTSP/Au-NPs/ GCE in which Au-nanoparticles were deposited for $600 \mathrm{~s}$. The dynamic linear calibration range of the HRP modified electrode is 1.4-78 $\mu \mathrm{M}$ with a correlation coefficient of 0.9994. Detection limit and response time to the continuous addition of hydrogen peroxide were observed to be $1.4 \mu \mathrm{M}$ and $c a .9-10 \mathrm{~s}$, respectively. This linearity is generally maintained up to a few $\mathrm{mM}$ of hydrogen peroxide. However, the amperometric response of the HRP immobilized GCEs remains constant as shown in Figure 8 when the $\mathrm{H}_{2} \mathrm{O}_{2}$ concentration is higher than $c a .3 \mathrm{mM}$. As an indicate of the enzyme-substrate kinetics, the apparent Michaelis-Menten constant $\left(\mathrm{K}_{\mathrm{M}}{ }^{\mathrm{app}}\right)$ can be estimated from the electrochemical 
analogue of the Lineweaver-Burk equation ${ }^{21}$ :

$$
1 / \mathrm{I}_{\mathrm{ss}}=1 / \mathrm{I}_{\max }+\mathrm{K}_{\mathrm{M}}^{\text {app }} / \mathrm{I}_{\max } \mathrm{C}
$$

where $\mathrm{I}_{\mathrm{sS}}$ is the steady-state current due to the addition of substrate, $\mathrm{C}$ is the bulk concentration of the substrate, and $\mathrm{I}_{\max }$ is the maximum current measured under saturated substrate condition. The slope and intercept in the plot of $1 / I_{s s} v s .1 / C$ provides value of $K_{M}^{\text {app }}$ for the HRP modified electrode. The values of $\mathrm{K}_{\mathrm{M}}{ }^{\text {app }}$ of the HRP/DTSP/Au-NPs/ GCEs in this work were found to be 1.86, 1.08, 0.78, and $0.69 \mathrm{mM}$ when the deposition time of Au-NP was 600, 120, 5 , and $3 \mathrm{~s}$, respectively.

These $\mathrm{K}_{\mathrm{M}}{ }^{\text {app }}$ values were smaller than those reported by Ju et $a .^{22}$ and Li et al. ${ }^{23}$ slightly larger than those by Chen et $a l .{ }^{7}$ and Yu et al. ${ }^{9}$ Our result indicates that HRP immobilized on the smaller sized Au-NP shows higher enzymatic activity and affinity for $\mathrm{H}_{2} \mathrm{O}_{2}$. The reason of smaller $\mathrm{Km}$ value for smaller size of Au-NPs might be due to smaller adsorption amount of HRP enzyme on DTSP monolayer. On the contrary, Chen et ll $^{7}$ reported that HRP adsorbed directly on the larger gold colloids shows higher activity and suggested that the higher activity may be ascribed to larger colloids providing more freedom in orientation and channels between the prosthetic groups of HRP and mediator molecules. Currently, we cannot address the difference in trend of nanoparticle size and enzyme activity. However, the trend difference might be due to substantially structural differences introduced in fabrication of HRP immobilized biosensor system: e.g. direct adsorption of HRP on gold colloids linked via formation of two Schiff base bridges between glutaraldehyde and cysteamine on gold electrode surface.

The size-dependent electrocatalytic behavior of Au-NPs is shown in Figure 10. The reduction current of hydrogen peroxide was divided by total surface area of Au-NPs on GCE and the electrocatalytic current density was plotted

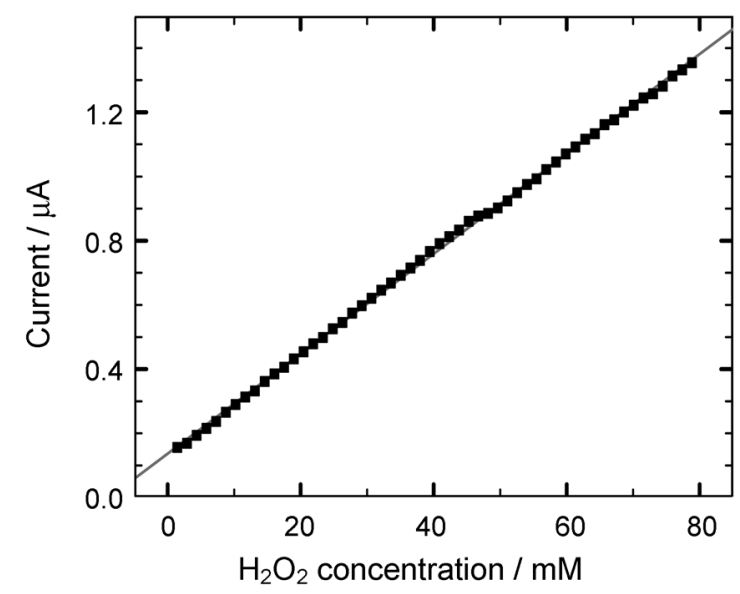

Figure 9. Linear calibration curve from the amperometric response of a HRP/DTSP/Au-NPs/GCE in which Au-NP was electrochemically deposited for $600 \mathrm{~s}$. Aliquot of $20 \mu \mathrm{L}$ of $0.365 \mathrm{mM} \mathrm{H}_{2} \mathrm{O}_{2}$ was successively added into $0.1 \mathrm{M}$ PBS containing $2.0 \mathrm{mM}$ hydroquinone.

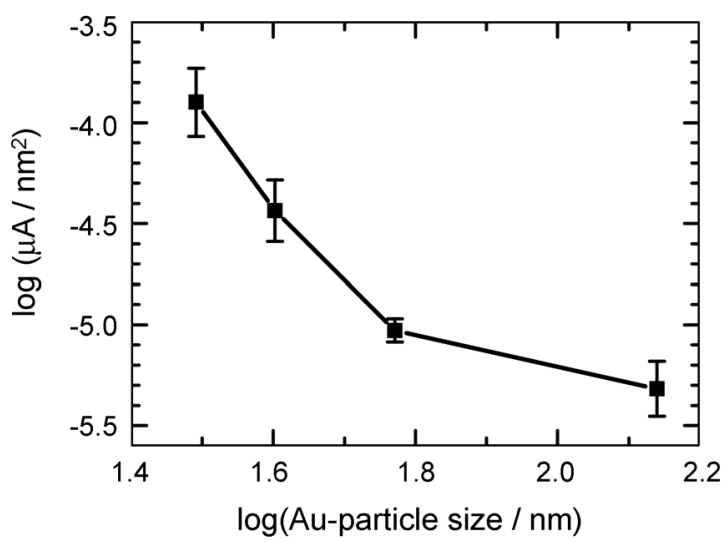

Figure 10. Plot of electrocatalytic current density of Au-NPs $v s$. Average nanoparticle size. Data were taken from Figure 8.

with respect to the average size of nanoparticles. The current density on the smaller sized Au-NPs is much higher than that on the larger sized nanoparticles on GCE. The effect of the particle size is due to the high surface area to volume ratio of Au-NPs in the biosensor. The similar size effects of HRP-labeled gold colloid with different sizes adsorbed on cysteamine monolayer, ${ }^{7}$ and trapped in mercaptoptopyltrimethoxysilane sol-gel network ${ }^{8}$ on gold have been reported for reduction of hydrogen peroxide. In these reports, $\mathrm{Au}$ colloids were not in direct contact with an electrode surface. The effect of the size of Au colloids with different sizes is attributed to the fact that the smaller-sized Au colloids could be more densely packed on the base monolayer than the larger-sized colloids, resulting in more active sites for the immobilization of electroactive self-assembled monolayer as Willner et $a l .^{24}$ reported.

\section{Conclusions}

We prepared an enzyme electrode based on the immobilization of HRP on dithiobis-N-succinimidylpropionate self-assembled monolayer formed on Au-nanoparticles which were electrochemically deposited onto glassy carbon electrode surface. The average size as well as total surface area of Au-NPs could be controlled by varying deposition time. The deposited Au-NPs were thermodynamically stable and durable enough to show good electrocatalytic behavior of $\mathrm{O}_{2}$ reduction. The HRP/DTSP/Au-NPs/GCEs show faster, more stable and sensitive amperometric response for $\mathrm{H}_{2} \mathrm{O}_{2}$ reduction than the HRP/DTSP/gold plate electrode in the presence of hydroquinone as a mediator. In the optimized experimental conditions, the HRP immobilized electrode incorporating smaller-sized Au-NPs showed higher electrocatalytic activity due to the high surface area to volume ratio of Au-NPs in the biosensor.

Acknowledgements. This work was supported by grant no. R01-2004-000-10988-0 from the Basic Research Program of the KOSEF. 


\section{References}

1. Willner, I.; Katz, E. Angew. Chem. Int. Ed. 2000, 39, 1180.

2. (a) Armstrong, F. A.; Wilson, G. S. Electrochim. Acta 2000, 46, 2623. (b) Yoon, K.-J.; Kwon H.-S.; Lee, B.-G. Bull. Korean Chem. Soc. 2005, 49, 325.

3. Gorton, L.; Lindgren, A.; Larsson, T.; Munteanu, F. D.; Ruzgas, T.; Gazaryan, I. Anal. Chim. Acta 1999, 400, 91

4. Ruzgas, T.; Elisabeth, C.; Emneus, J.; Gorton, L.; Marko-Varga, G. Anal. Chim. Acta 1996, 330, 123 .

5. Crumbliss, A. L.; Perine, S. C.; Stonehuerner, J.; Tubergen, K. R.; Zhao, J.; Henkens, R. W.; O’Daly, J. P. Biotechnol. Bioeng. 1992, $40,483$.

6. Zhao, J.; Henkens, R. W.; Stonehuerner, J.; O'Daly, J. P.; Crumbliss, A. L. J. Electroanal. Chem. 1992, 327, 109.

7. Xiao, Y.; Ju, H.-X.; Chen, H.-Y. Anal. Chim. Acta 1999, 391, 73.

8. Jia, J.; Wang, B.; Wu, A.; Cheng, G.; Li, Z.; Dong, S. Anal. Chem. 2002, 74, 2217

9. Lei, C.-X.; Hu, S.-Q.; Shen, G.-L.; Yu, R.-Q. Talanta 2003, 59, 981

10. Lei, C.-X.; Wang, H.; Shen, G.-L.; Yu, R.-Q. Electroanal. 2004, 16,736 .

11. Ulman, A. An Introduction to Ultrathin Organic Films from
Langmuir-Blodgett to Self-Assembly; Academic Press: New York, 1991.

12. Finot, M. F.; Braybrook, G. D.; McDermott, M. T. J. Electroanal. Chem. 1999, 466, 234.

13. Finot, M. F.; McDermott, M. T. J. Electroanal. Chem. 2000, 488, 125.

14. Nelson, D. P.; Kiesov, L. A. Anal. Biochem. 1972, 49, 474

15. Creager, S. E.; Hockett, L. A.; Rowe, G. K. Langmuir 1992, 8 , 854.

16. Darder, M.; Takada, K.; Pariente, F.; Lorenzo, E.; Abruna, H. D. Anal. Chem. 1999, 71, 5530.

17. El-Deab, M. S.; Okajima, T.; Ohsaka, T. J. Electrochem. Soc. 2003, 150, A851

18. Kozlowska, H. A.; Conway, B. E.; Hamelin, A.; Stoicoviciu, L. J. Electroanal. Chem. Interfacial Electrochem. 1987, 228, 429.

19. Oungpipat, W.; Alexander, P. W.; Southwell-Keely, P. Anal. Chim Acta 1995, 309, 35.

20. Maehly, A. C. Plant Peroxidases: Methods in Enzymology; Academic Press: New York, 1995; vol. 11, p 807.

21. Kamin, R. A.; Wilson, G. S. Anal. Chem. 1980, 52, 1198.

22. Liu, S.-Q.; Ju, H.-X. Anal. Biochem. 2002, 307, 110

23. Xu, Y.; Peng, W.; Liu, X.; Li, G. Biosens. Bioelectron 2004, 20, 533.

24. Doron, A.; Katz, E.; Willner, I. Langmuir 1995, 11, 1313. 